\title{
Hemithorax Opacification \& Large Volume Thoracentesis: A Novel Predictor of Re-Expansion Pulmonary Edema
}

\author{
Victor E Prado, $M^{1^{*}}$, Shasha X Chen, $\mathrm{DO}^{2}$, Anupam Basu, $M D^{3}$, Connor J Wakefield, BS ${ }^{4}$, Shashvat \\ Sukhal, $M D^{5}$, Sanjay A Patel, $M D^{6}$ and Sean B Smith, $M D^{7}$
}

${ }^{1}$ Department of Internal Medicine, University of Cincinnati, USA

${ }^{2}$ Division of Postgraduate Education, Department of Medicine, Cook County Health, USA

${ }^{3}$ Department of Radiology, Cook County Health, USA

${ }^{4}$ Rush Medical College, USA

${ }^{5}$ Division of Pulmonary and Critical Care Medicine, Department of Medicine, Cook County Health, USA

${ }^{6}$ Department of Graduate Medical Education, Riverside Methodist Hospital (Ohio Health), USA

${ }^{7}$ Division of Pulmonary and Critical Care Medicine, Department of Medicine, Northwestern University, USA

*Corresponding author: Victor E Prado, MD, Department of Medicine, University of Cincinnati, 231 Albert Sabin Way, Suite 7559, Cincinnati, OH 45267, USA, Tel: (513)-558-5608

\begin{abstract}
Introduction: Symptomatic pleural effusions are a common reason for hospital visits. Guidelines recommend draining < $1.5 \mathrm{~L}$ with large-volume thoracentesis (LVT) to avoid re-expansion pulmonary edema (REPE). Hemithorax opacification by pleural fluid on chest X-ray (CXR) has not been studied as predictor of REPE. We evaluated the incidence of REPE using hemithorax opacification on CXR.

Methods: We reviewed LVTs with pre- and post-procedural chest CXR from 2008 to 2019 at a tertiary urban hospital. Image $\mathrm{J}$ software was used to calculate the percentage of hemithorax opacification before and after drainage. CXRs were independently reviewed by a radiologist and interventional pulmonologist-both blinded to clinical data. Clinical REPE was separately according to clinical signs and symptoms.

Results: 198 LVTs with CXRs were reviewed. Median volume drained was $1.8 \mathrm{~L}$ (IQR 1.6 L-2.0 L) and median percent opacification drained was $26 \%$ (IQR $13-40 \%$ ): $11.1 \%$ of cases drained $>50 \%$ opacification, and $17.7 \%$ had complete drainage. 177 post-procedural CXRs were amenable for evaluation and $20.3 \%$ had evidence of radiographic REPE. In those with radiographic REPE, $2.5 \%$ had clinical REPE. Multivariate regression analysis demonstrated that draining $>50 \%$ of the opacified hemithorax was associated with radiographic REPE (OR 3.51, 95\% Cl 1.09-11.26, $p=$ 0.035 ) and clinical REPE (OR 11.22, 95\% Cl 1.67-75.16, $p$ $=0.013$ ).
\end{abstract}

Conclusion: Radiographic REPE was relatively common, but often without symptoms. The reduction of $>50 \%$ of hemithorax opacification is a novel predictor of REPE. We suggest individualizing limitations of fluid removal according to hemithorax opacification and clinical scenario rather than an arbitrary cutoff of $1.5 \mathrm{~L}$.

\section{Keywords}

Large-volume thoracentesis, Pleural effusion, Re-expansion pulmonary edema, Bedside procedures

\section{Introduction}

Symptomatic large pleural effusions are frequent among patients presenting to the emergency department, often necessitating inpatient admission. The theoretical benefits of complete drainage of pleural effusions include symptomatic relief, avoidance of multiple procedures, achieving complete lung expansion, and preventing residual pleural space disease [1].

Re-expansion pulmonary edema (REPE) is a welldescribed but uncommon complication seen following expansion of a compressed lung after a large amount of pleural fluid is rapidly evacuated [2,3]. It is hypothesized that REPE develops after a rapid change in transpleural pressure with subsequent engorgement of 
Table 1: Patient characteristics on admission.

\begin{tabular}{|c|c|}
\hline Patient characteristics & $\begin{array}{l}\text { Baseline } \\
\text { results }\end{array}$ \\
\hline Age (years) & $56(48-63)$ \\
\hline Female & $30.8 \%$ \\
\hline \multicolumn{2}{|l|}{ Race } \\
\hline African American & $40.4 \%$ \\
\hline Hispanic & $32.8 \%$ \\
\hline Caucasian & $20.7 \%$ \\
\hline Other & $6.1 \%$ \\
\hline Smoking history & $53.0 \%$ \\
\hline \multicolumn{2}{|l|}{ Effusion characteristics } \\
\hline Massive & $19.7 \%$ \\
\hline Malignant & $64.6 \%$ \\
\hline Exudative & $72.7 \%$ \\
\hline Right-sided & $67.7 \%$ \\
\hline Initial diagnosis & $35.9 \%$ \\
\hline Duration (weeks) & $4(2-8)$ \\
\hline Duration $>4$ weeks & $70.2 \%$ \\
\hline \multicolumn{2}{|l|}{ Etiologies of effusion } \\
\hline Renal disease & $4.55 \%$ \\
\hline Hepatic hydrothorax & $14.14 \%$ \\
\hline Heart failure & $8.08 \%$ \\
\hline Malignancy & $64.65 \%$ \\
\hline Infection & $4.55 \%$ \\
\hline Pancreatitis & $2.02 \%$ \\
\hline Other & $2.02 \%$ \\
\hline \multicolumn{2}{|l|}{ Comorbidities } \\
\hline Anemia $(\mathrm{Hgb}<10 \mathrm{~g} / \mathrm{dL})$ & $27.8 \%$ \\
\hline Atrial fibrillation & $9.1 \%$ \\
\hline Chronic renal disease & $15.7 \%$ \\
\hline Cirrhosis & $18.7 \%$ \\
\hline Coronary disease & $11.6 \%$ \\
\hline Diabetes & $26.3 \%$ \\
\hline Heart failure & $13.6 \%$ \\
\hline Hypertension & $49.0 \%$ \\
\hline Hypoalbuminemia (Albumin $<2.5 \mathrm{~g} / \mathrm{dL}$ ) & $18.7 \%$ \\
\hline Obesity & $22.2 \%$ \\
\hline
\end{tabular}

intrapulmonary lymphatic and interstitial fluid. The duration of lung compression, the rate of expansion, and the pressure gradient have been associated with REPE development $[4,5]$. REPE can be detected radiologically in the absence of symptoms (i.e., radiographic REPE), with an incidence ranging from $<5 \%$ to $14 \%[3,6]$. When associated with clinical symptoms (e.g., cough, new or worsening hypoxia or hypotension, or chest pains), then it is characterized as clinical REPE. Although clinical REPE occurs after $<1 \%$ of thoracentesis, the mortality rate has been reported as high as $20 \%$ [7-9].

In order to avoid REPE, guidelines recommend that fluid drainage be limited to removal of $<1.5 \mathrm{~L}$ during a single large-volume thoracentesis (LVT), especially in the absence of pleural manometry [10]. Pleural manometry allows providers to limit changes in trans-pleural pressure, but it is rarely performed in general practice. We therefore considered whether percent opacification of the hemithorax by fluid on chest X-ray (CXR) before and after LVT may be associated with REPE.

\section{Materials and Methods}

We retrospectively reviewed patients who underwent thoracentesis performed by a dedicated bedside procedure service at our tertiary-care, urban medical center from 2008 to 2019. Institutional review board approval was obtained, and informed consent was waived (Study 19-208). Patients' demographics, comorbidities, laboratory studies, and outcomes were reviewed (Table 1 ). We included patients who had $\geq 1.5$ $L$ fluid removed with LVT and also had CXR before and within 36 hours after LVT. The procedure service was staffed by procedure-trained hospitalists. Procedures were performed under static ultrasound guidance, but pleural manometry was not routinely performed. Fluid was either drained to gravity or by manual evacuation. The volume of fluid and the etiologies of the effusions were catalogued. Any prior imaging that was available was reviewed to determine the duration of the effusion prior to index drainage. Image J software (National Institute of Health, Bethesda, MD) was used to calculate the percent opacification of the hemithorax on CXR before and after LVT (Figure 1 and Table 2). A massive effusion was defined as $>80 \%$ initial opacification of the hemithorax prior to LVT, and complete drainage was defined by $<10 \%$ residual opacification after LVT.

Pre and post-procedural CXRs were independently reviewed by a board-certified radiologist and a boardcertified interventional pulmonologist, both of whom were blinded to clinical data. Radiographic REPE was defined as the presence of alveolar opacities on CXR consistent with pulmonary edema in lobes that had previously been opacified by the effusion. The radiologist was first asked to determine whether a meaningful assessment of REPE could be made based on the quality of the CXR. For those CXRs deemed reasonable for assessment, the image reviewers each assigned a numerical score regarding the presence of REPE: 0 for no evidence of REPE; 1 for possible REPE; and 2 for likely REPE. A total score for each CXR was calculated, and those with a score $\geq 3$ were considered to have radiographic REPE. Clinical REPE was defined as a significant post-procedural clinical event that occurred in the presence of radiographic REPE. Significant clinical events included development of acute respiratory symptoms (cough, dyspnea, or chest pain), newonset hypoxia requiring treatment, or hemodynamic instability. Pneumothoraces were catalogued, and a pneumothorax ex vacuo was defined as the presence of dependent or basilar air in the pleura after LVT 


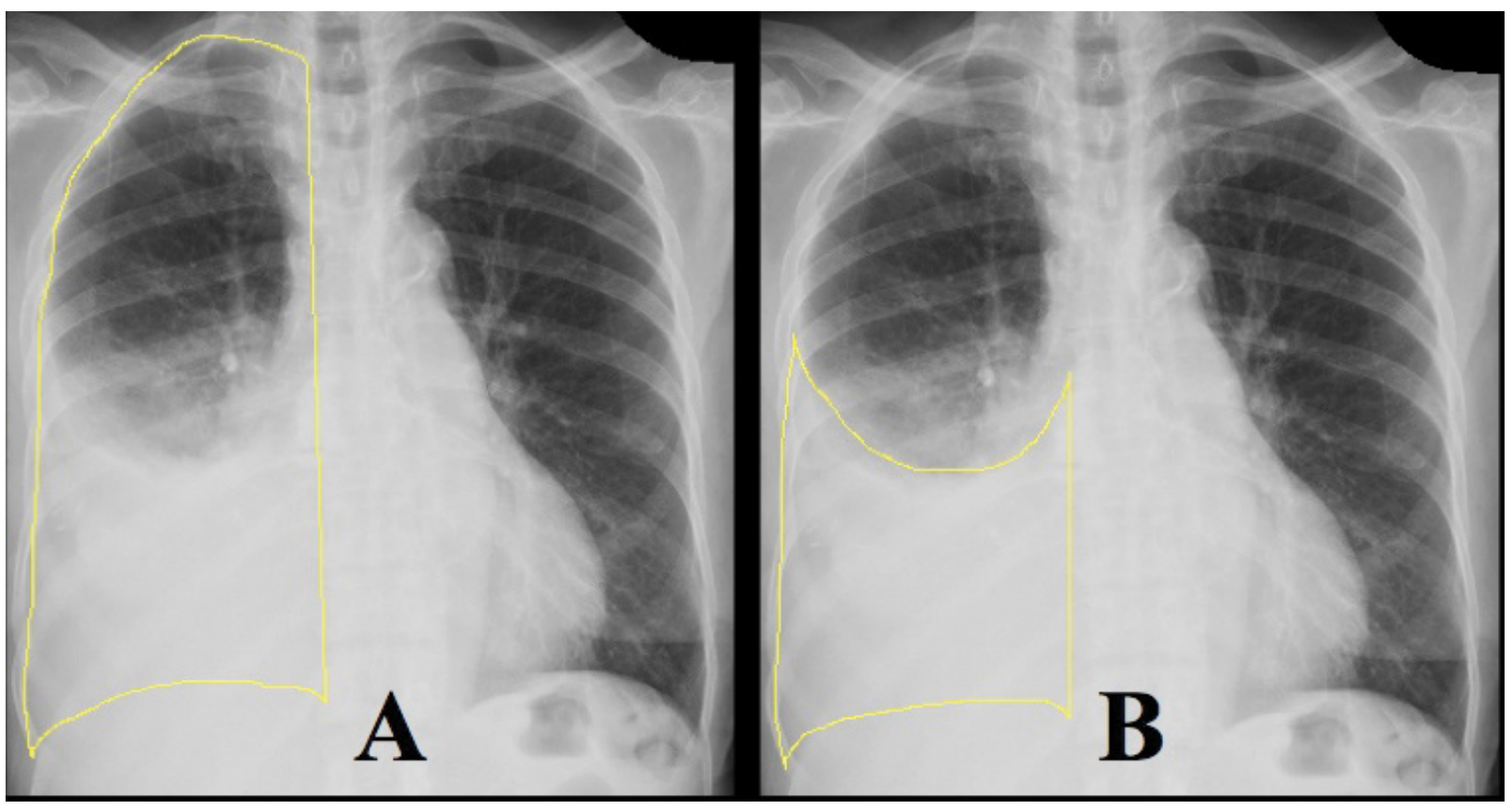

Figure 1: Quantifying opacification of hemithorax. Image $\mathrm{J}$ software was used to determine the percentage of the hemithorax that was opacified by pleural effusion. Panel A shows the first measurement of the entire hemithorax. Panel B shows the second measurement of the effusion. Percent opacification was calculated by dividing the second measurement by the first.

Table 2: Radiographic characteristics.

\begin{tabular}{|l|l|}
\hline Radiology data & Results \\
\hline Pre-procedure opacification (\%) & $55(40-74)$ \\
\hline Post-procedure opacification (\%) & $25(14-45)$ \\
\hline Drainage (\%) & $26(13-40)$ \\
\hline Drained > 50\% & $11.1 \%$ \\
\hline Complete drainage & $17.7 \%$ \\
\hline REPE Scores & \\
\hline CXR could be assessed & $89.4 \%$ \\
\hline Score & $2(0-2)$ \\
\hline Score $\geq 3$ & $20.3 \%$ \\
\hline
\end{tabular}

CXR: Chest X-ray

with thickening of the visceral pleural to suggest an underlying trapped lung.

\section{Results}

From 2008 to 2019, we identified 198 LVT that had CXRs following the procedure. Patients had a median (interquartile range [IQR]) age of 56 years (IQR 48$63)$, and 61 (30.8\%) were women. Eighty (40.4\%) were African American, 65 (32.8\%) Hispanic, and 41 (20.7\%) Caucasian. The majority $(67.7 \%)$ were rightsided effusions, and $72.7 \%$ were exudative. The most common etiology was malignancy (64.6\%), followed by hepatic hydrothorax (14.1\%), and heart failure (8.1\%). Thirty-nine (19.7\%) were considered massive effusions, and median volume drained of 1.8L (IQR 1.60-2.0L). Seventy-one (35.9\%) presented with no prior imaging, thus the duration of those effusions could not be
Table 3: Study outcomes.

\begin{tabular}{|l|l|l|}
\hline Outcomes & All patients & $\begin{array}{l}\text { Patients with } \\
\text { radiographic } \\
\text { REPE }\end{array}$ \\
\hline Any clinical event & $10.1 \%$ & $2.5 \%$ \\
\hline New symptoms & $6.6 \%$ & $2.0 \%$ \\
\hline Hypotension & $2.5 \%$ & $0.5 \%$ \\
\hline Hypoxia & $5.6 \%$ & $1.5 \%$ \\
\hline ICU admission & $3.5 \%$ & $1.0 \%$ \\
\hline Shock & $1.5 \%$ & $0.5 \%$ \\
\hline Non-invasive ventilation & $1.0 \%$ & $0.0 \%$ \\
\hline Intubation & $0.5 \%$ & $0.0 \%$ \\
\hline Death & $2.5 \%$ & $1.0 \%$ \\
\hline
\end{tabular}

ICU: Intensive Care Unit

determined. The remaining cases had a median effusion duration of 4 weeks (IQR 2-8). The most common comorbidities included hypertension (49.0\%), anemia $(27.8 \%)$, diabetes $(26.3 \%)$, and obesity $(22.2 \%)$. Over half (53.0\%) had a history of smoking.

Median percent opacification of the hemithorax prior to LVT was $55 \%$ (IQR 40-74\%), and median opacification after LVT was 25\% (IQR 14-45\%) (Table 2). Median percent drained was $26 \%$ (IQR $13-40 \%) ; 11.1 \%$ of cases drained $>50 \%$ of the opacification, and $17.7 \%$ of cases had complete drainage. The radiologist identified 177 (89.4\%) post-procedural CXRs that could be assessed for REPE. The most common reason for excluding a CXR was a significant amount of post-procedural pleural fluid that appeared similar to the pre-procedural CXR. 
Amongst those 21 excluded CXRs, the median post-procedural opacification was $83 \%$ (IQR $64-100 \%)$. For the 177 included CXRs, the median summation score was 2 (IQR 0-2), and 36 (20.3\%) CXRs had a score $\geq 3$ consistent with radiographic REPE. There was $44.1 \%$ overall agreement between the reviewers for the radiographic interpretation for REPE (kappa 0.18, $p<0.001$ ).

Twenty patients (10.1\%) had new clinical symptoms after LVT, but only $2.5 \%$ had both radiographic and clinical evidence of REPE (Table 3). The most common events were new respiratory symptoms (2.0\%), hypoxia (1.5\%), and hypotension (0.5\%). No patients with clinical REPE required non-invasive ventilation or intubation. Two patients with clinical REPE (1.0\%) died during their hospitalizations, but deaths were not immediately related to REPE. Twenty-one (10.6\%) were found to have pneumothoraces after LVT, with the majority of these $(n=17)$ meeting criteria for pneumothoraces ex vacuo.

There was an association between the percent change in opacification of the hemithorax and both radiographic and clinical REPE. The percent change in opacification was higher for cases with radiographic REPE $(40 \%$, IQR $31-52 \%)$ compared to those without radiographic REPE $(24 \%, 12-38 \%)(p<0.001)$. The percent change in opacification was also higher for cases with clinical REPE (51\%, IQR 31-54\%) compared to those without clinical REPE $(25 \%, 12-40 \%)(p=0.047)$. Multivariate

Table 4: Univariate and multivariate analysis of radiographic REPE.

\begin{tabular}{|c|c|c|c|c|c|c|c|c|c|c|}
\hline \multirow{3}{*}{$\begin{array}{l}\text { Patient } \\
\text { characteristics } \\
\text { Age > } 65 \text { years }\end{array}$} & \multirow{3}{*}{\begin{tabular}{|l|} 
Incidence \\
$20.2 \%$ \\
\end{tabular}} & \multirow{3}{*}{$\begin{array}{l}\text { Radiographic } \\
\text { REPE } \\
25.0 \% \\
\end{array}$} & \multicolumn{4}{|c|}{ Univariate analysis } & \multicolumn{4}{|c|}{ Multivariate analysis } \\
\hline & & & \multirow{2}{*}{\begin{tabular}{|l|} 
OR \\
1.41
\end{tabular}} & \multicolumn{2}{|c|}{$95 \% \mathrm{Cl}$} & \multirow{2}{*}{\begin{tabular}{|l|} 
p-value \\
0.438 \\
\end{tabular}} & \multirow[t]{2}{*}{ OR } & \multicolumn{2}{|c|}{$95 \% \mathrm{Cl}$} & \multirow[t]{2}{*}{ p-value } \\
\hline & & & & 0.59 & 3.34 & & & & & \\
\hline Female & $30.8 \%$ & $20.8 \%$ & 1.04 & 0.47 & 2.30 & 0.928 & & & & \\
\hline \multicolumn{11}{|l|}{ Race } \\
\hline African American & $40.4 \%$ & $23.3 \%$ & 1.00 & 1.00 & 1.00 & -- & & & & \\
\hline Hispanic & $32.8 \%$ & $21.7 \%$ & 0.91 & 0.40 & 2.07 & 0.824 & & & & \\
\hline Caucasian & $20.7 \%$ & $15.2 \%$ & 0.59 & 0.20 & 1.76 & 0.342 & & & & \\
\hline Other & $6.1 \%$ & $9.1 \%$ & 0.33 & 0.04 & 2.76 & 0.306 & & & & \\
\hline Smoking history & $53.0 \%$ & $22.3 \%$ & 1.30 & 0.62 & 2.73 & 0.482 & & & & \\
\hline \multicolumn{11}{|c|}{ Effusion characteristics } \\
\hline Massive & $19.7 \%$ & $45.0 \%$ & 3.94 & 1.49 & 10.43 & 0.006 & 2.12 & 0.65 & 6.94 & 0.215 \\
\hline Malignant & $64.6 \%$ & $16.8 \%$ & 0.56 & 0.27 & 1.17 & 0.124 & & & & \\
\hline Exudative & $72.7 \%$ & $18.0 \%$ & 0.61 & 0.28 & 1.32 & 0.208 & & & & \\
\hline Right-sided & $67.7 \%$ & $21.7 \%$ & 1.30 & 0.58 & 2.92 & 0.525 & & & & \\
\hline Initial diagnosis & $35.9 \%$ & $20.6 \%$ & 1.03 & 0.48 & 2.21 & 0.942 & & & & \\
\hline Duration $>4$ weeks & $70.2 \%$ & $21.1 \%$ & 1.18 & 0.52 & 2.66 & 0.690 & & & & \\
\hline \multicolumn{11}{|l|}{ Drainage data } \\
\hline Drained > 50\% & $11.1 \%$ & $45.5 \%$ & 4.13 & 1.62 & 10.57 & 0.003 & 3.51 & 1.09 & 11.26 & 0.035 \\
\hline Complete drainage & $17.7 \%$ & $22.9 \%$ & 1.21 & 0.50 & 2.94 & 0.680 & & & & \\
\hline Pneumothorax & $10.6 \%$ & $25.0 \%$ & 1.35 & 0.46 & 4.01 & 0.584 & & & & \\
\hline $\begin{array}{l}\text { Pneumothorax ex } \\
\text { vacuo }\end{array}$ & $8.6 \%$ & $23.5 \%$ & 1.23 & 0.38 & 4.03 & 0.731 & & & & \\
\hline \multicolumn{11}{|l|}{ Comorbidities } \\
\hline Anemia & $27.8 \%$ & $23.1 \%$ & 1.20 & 0.55 & 2.63 & 0.649 & & & & \\
\hline Atrial fibrillation & $9.1 \%$ & $23.5 \%$ & 1.23 & 0.38 & 4.03 & 0.731 & & & & \\
\hline Chronic renal disease & $15.7 \%$ & $25.0 \%$ & 1.38 & 0.54 & 3.55 & 0.506 & & & & \\
\hline Cirrhosis & $18.7 \%$ & $19.4 \%$ & 0.93 & 0.35 & 2.47 & 0.881 & & & & \\
\hline Coronary disease & $11.6 \%$ & $31.8 \%$ & 2.03 & 0.76 & 5.42 & 0.159 & & & & \\
\hline Diabetes & $26.3 \%$ & $26.5 \%$ & 1.65 & 0.76 & 3.59 & 0.208 & & & & \\
\hline Heart failure & $13.6 \%$ & $26.9 \%$ & 1.55 & 0.60 & 4.03 & 0.369 & & & & \\
\hline Hypertension & $49.0 \%$ & $100.0 \%$ & 2.19 & 1.03 & 4.67 & 0.042 & 2.60 & 1.15 & 5.85 & 0.021 \\
\hline Hypoalbuminemia & $18.7 \%$ & $23.5 \%$ & 1.21 & 0.48 & 3.00 & 0.688 & & & & \\
\hline Obesity & $22.2 \%$ & $18.9 \%$ & 1.06 & 0.41 & 2.72 & 0.903 & & & & \\
\hline
\end{tabular}

REPE: Re-expansion Pulmonary Edema; OR: Odds Ratio; Cl: Confidence Interval 
regression analysis demonstrated that draining > $50 \%$ of the opacified hemithorax was associated with radiographic (OR 3.51,95\% $\mathrm{Cl} 1.09-11.26, \mathrm{p}=0.035$ ) and clinical REPE (OR 11.22, 95\% Cl 1.67-75.16, $p=0.013$ ) (Table 4 and Table 5). Hypertension was also associated with radiographic (OR $2.60,95 \% \mathrm{Cl} 1.15-5.85, \mathrm{p}=0.021$ ) but not clinical REPE. Pneumothorax ex vacuo was associated with clinical REPE in univariate modeling (OR 7.91, 95\% Cl 1.23-51.08, $p=0.030$ ) but did not meet statistical significance in the multivariate model (OR $5.55,95 \% \mathrm{Cl} 0.75-40.81, \mathrm{p}=0.092$ ). There were no other predictors of radiographic or clinical REPE.

\section{Discussion}

As previously described, the incidence of radiographic REPE in our cohort was more common than clinical
REPE (20.3\% vs. $2.5 \%)$, and the majority of REPE cases were mild and did not result in morbidity or mortality. Guidelines suggest limiting LVT drainage to $1.5 \mathrm{~L}$ in order to avoid REPE, especially in manometry is not used, but our analysis is the first to consider percent opacification of hemithorax as part of REPE assessment.

Reports about REPE were initially described after a negative pressure of $-20 \mathrm{mmHg}$ was applied through a chest tube [5]. Concern that REPE was related to fluid volume removal was first described by Light, et al. who suggested that volume be limited to $1.0 \mathrm{~L}$ and that REPE may not be associated with pressure changes [11]. However, Villena, et al. found that larger fluid volume could be removed without REPE if fluid drainage was stopped at pleural pressure of $-20 \mathrm{cmH}_{2} \mathrm{O}$ [12].

Table 5: Univariate and multivariate analysis of clinical REPE.

\begin{tabular}{|c|c|c|c|c|c|c|c|c|c|c|}
\hline \multirow{3}{*}{\begin{tabular}{|l} 
Patient characteristics \\
Age $>65$ years \\
\end{tabular}} & \multirow{3}{*}{\begin{tabular}{|l} 
Incidence \\
$20.2 \%$ \\
\end{tabular}} & \multirow{3}{*}{$\begin{array}{l}\text { Clinical } \\
\text { REPE }\end{array}$} & \multicolumn{4}{|c|}{ Univariate analysis } & \multicolumn{4}{|c|}{ Multivariate analysis } \\
\hline & & & \multirow{2}{*}{\begin{tabular}{|l} 
OR \\
0.99
\end{tabular}} & \multicolumn{2}{|c|}{$95 \% \mathrm{Cl}$} & \multirow{2}{*}{\begin{tabular}{|l|} 
p-value \\
0.991 \\
\end{tabular}} & \multirow[t]{2}{*}{ OR } & \multicolumn{2}{|c|}{$95 \% \mathrm{Cl}$} & \multirow[t]{2}{*}{ p-value } \\
\hline & & & & 0.11 & 9.08 & & & & & \\
\hline Female & $30.8 \%$ & $0.0 \%$ & -- & -- & -- & -- & & & & \\
\hline \multicolumn{11}{|l|}{ Race } \\
\hline African American & $40.4 \%$ & $2.5 \%$ & 1.00 & 1.00 & 1.00 & -- & & & & \\
\hline Hispanic & $32.8 \%$ & $1.5 \%$ & 0.61 & 0.05 & 6.87 & 0.689 & & & & \\
\hline Caucasian & $20.7 \%$ & $2.4 \%$ & 0.98 & 0.09 & 11.08 & 0.984 & & & & \\
\hline Other & $6.1 \%$ & $8.3 \%$ & 3.55 & 0.30 & 42.42 & 0.318 & & & & \\
\hline Smoking history & $53.0 \%$ & $2.9 \%$ & 1.34 & 0.22 & 8.19 & 0.753 & & & & \\
\hline \multicolumn{11}{|l|}{ Effusion characteristics } \\
\hline Massive & $19.7 \%$ & $5.1 \%$ & 2.81 & 0.45 & 17.43 & 0.267 & & & & \\
\hline Malignant & $64.6 \%$ & $2.3 \%$ & 0.82 & 0.13 & 5.00 & 0.826 & & & & \\
\hline Exudative & $72.7 \%$ & $2.1 \%$ & 0.55 & 0.09 & 3.40 & 0.523 & & & & \\
\hline Right-sided & $67.7 \%$ & $3.0 \%$ & 1.94 & 0.21 & 17.70 & 0.558 & & & & \\
\hline Initial diagnosis & $35.9 \%$ & $2.8 \%$ & 1.20 & 0.20 & 7.34 & 0.845 & & & & \\
\hline Duration > 4 weeks & $70.2 \%$ & $2.2 \%$ & 0.64 & 0.10 & 3.93 & 0.630 & & & & \\
\hline \multicolumn{11}{|l|}{ Drainage data } \\
\hline Drained $>50 \%$ & $11.1 \%$ & $13.6 \%$ & 13.74 & 2.16 & 87.43 & 0.006 & 11.22 & 1.67 & 75.16 & 0.013 \\
\hline Complete drainage & $17.7 \%$ & $5.7 \%$ & 3.23 & 0.52 & 20.11 & 0.208 & & & & \\
\hline Pneumothorax & $10.6 \%$ & $14.3 \%$ & 14.58 & 2.28 & 93.10 & 0.005 & & & & \\
\hline Pneumothorax ex vacuo & $8.6 \%$ & $11.8 \%$ & 7.91 & 1.23 & 51.08 & 0.030 & 5.55 & 0.75 & 40.81 & 0.092 \\
\hline \multicolumn{11}{|l|}{ Comorbidities } \\
\hline Anemia & $27.8 \%$ & $5.5 \%$ & 3.92 & 0.64 & 24.15 & 0.140 & & & & \\
\hline Atrial fibrillation & $9.1 \%$ & $0.0 \%$ & -- & -- & -- & -- & & & & \\
\hline Chronic renal disease & $15.7 \%$ & $3.2 \%$ & 1.36 & 0.15 & 12.58 & 0.787 & & & & \\
\hline Cirrhosis & $18.7 \%$ & $0.0 \%$ & -- & -- & -- & -- & & & & \\
\hline Coronary disease & $11.6 \%$ & $4.3 \%$ & 1.94 & 0.21 & 18.18 & 0.560 & & & & \\
\hline Diabetes & $26.3 \%$ & $1.9 \%$ & 0.70 & 0.08 & 6.37 & 0.748 & & & & \\
\hline Heart failure & $13.6 \%$ & $7.4 \%$ & 4.48 & 0.71 & 28.15 & 0.110 & & & & \\
\hline Hypertension & $49.0 \%$ & $2.1 \%$ & 0.69 & 0.11 & 4.21 & 0.685 & & & & \\
\hline Hypoalbuminemia & $18.7 \%$ & $2.7 \%$ & 1.22 & 0.12 & 12.11 & 0.864 & & & & \\
\hline Obesity & $22.2 \%$ & $4.5 \%$ & 6.29 & 0.56 & 71.07 & 0.137 & & & & \\
\hline
\end{tabular}

REPE: Re-expansion Pulmonary Edema; OR: Odds Ratio; Cl: Confidence Interval 
Association between intrapleural pressures and symptoms was further assessed in a series of 169 patients, which revealed that a vague chest discomfort was associated with reduced pleural pressures and subsequently a sign to terminate the thoracentesis [13]. Based on the findings described, many medical centers have obtained safe results by interrupting the procedure when intrapleural pressure falls below $-20 \mathrm{cmH}_{2} \mathrm{O}$, patient develops chest discomfort, or there is no more fluid to drain $[9,14]$. However, a recent randomized clinical trial showed that routine pleural manometry did not prevent serious complications or provide clinical benefits and therefore did not recommend routine use of manometry [15]. Based on our study, a drainage > $50 \%$ of the opacified hemithorax seems to be associated with radiographic REPE and predicted development of clinical REPE. These findings might be related to rapid change in intrapleural pressures rather than the amount of volume removed.

We believe that radiographic REPE may be more common than our findings suggest since post-procedure CXRs are not always required and when obtained may be obscured by significant residual fluid which impairs REPE assessment $[16,17]$. The pre-procedural median opacification was $55 \%$, but only the minority of patients had significant pleural drainage: $11.1 \%$ had a decrease $>50 \%$; and only $17.7 \%$ had complete drainage. Although it was not described in the procedural report, we suspect that drainage was frequently terminated in most cases due to symptom onset with concern for REPE development or pneumothorax.

There are certain limitations to note on the findings from this retrospective study. First, many patients included did not have post-procedure imaging; therefore, incidence of radiographic REPE may be higher than $20.3 \%$. As described above, since the procedures were not done by the Interventional Pulmonology service, rate of complications may be higher compared to previous studies where procedures were done by an interventional pulmonologist. Also, a minority of patients had available imaging studies before presentation to document chronicity of effusion. Finally, since this was a retrospective review standardized clinical assessment during thoracentesis was not conducted which makes it difficult to determine why procedures were prematurely stopped.

\section{Conclusion}

In conclusion, even though radiographic REPE may represent a relatively common complication after LVT, the vast majority of cases are not clinically evident and therefore treatment is not necessary. In most cases of clinical REPE, symptoms require supportive management with the development of significant morbidity and mortality being rarely reported. We believe that drainage of pleural effusions should be continued to remove as much fluid as tolerated and there is no evidence of markedly decreased in intrapleural pressures determined by either manometry or patient symptoms. In patients who undergo LVT, we also suggest monitoring for respiratory symptoms in those who have a reduction in hemithorax opacification greater than $50 \%$ given possible risk for REPE. Limitations of fluid removal should be individualized according to hemithorax opacification rather than limited by an arbitrary volume cutoff.

\section{Disclosures}

The authors report no personal, financial, commercial, or otherwise related conflicts of interest to the data collection, analysis, or publication of this study.

\section{Funding}

None.

\section{Acknowledgements}

SAP, VEP \& SBS developed the study design. VEP, $S X C, A B \&$ SS contributed in the data collection. SBS, CJW \& VEP provided statistical analysis. SAP, VEP, SBS, \& SS contributed to the manuscript writing. All authors have seen and approved the final manuscript for submission.

\section{References}

1. Feller Kopman D (2007) Therapeutic thoracentesis: The role of ultrasound and pleural manometry. Curr Opin Pulm Med 13: 312-318.

2. Miller WC, Toon R, Palat H, Lacroix J (1973) Experimental pulmonary edema following re-expansion of pneumothorax. Am Rev Respir Dis 108: 654-656.

3. Ault MJ, Rosen BT, Scher J, Feinglass J, Barsuk JH (2015) Thoracentesis outcomes: A 12-year experience. Thorax 70: 127-132.

4. Sohara $Y$ (2008) Reexpansion pulmonary edema. Ann Thorac Cardiovasc Surg 14: 205-209.

5. Pavlin J, Cheney FW Jr (1979) Unilateral pulmonary edema in rabbits after reexpansion of collapsed lung. J Appl Physiol Respir Environ Exerc Physiol 46: 31-35.

6. Matsuura $\mathrm{Y}$, Nomimura T, Murakami H, Matsushima T, Kakehashi M, et al. (1991) Clinical analysis of reexpansion pulmonary edema. Chest 100: 1562-1566.

7. Tarver RD, Broderick LS, Conces DJ Jr (1996) Reexpansion pulmonary edema. J Thorac Imaging 11: 198-209.

8. Mahfood S, Hix WR, Aaron BL, Blaes P, Watson DC (1988) Reexpansion pulmonary edema. Ann Thorac Surg 45: 340345.

9. Feller-Kopman D, Berkowitz D, Boiselle P, Ernst A (2007) Large-volume thoracentesis and the risk of reexpansion pulmonary edema. Ann Thorac Surg 84: 1656-1661.

10. Havelock T, Teoh R, Laws D, Gleeson F, Group BTSPDG (2010) Pleural procedures and thoracic ultrasound: British Thoracic Society Pleural Disease Guideline 2010. Thorax 65: 61-76.

11. Light RW, Jenkinson SG, Minh VD, George RB (1980) Observations on pleural fluid pressures as fluid is withdrawn during thoracentesis. Am Rev Respir Dis 121: 799-804. 
12. Villena V, Lopez-Encuentra A, Pozo F, De-Pablo A, MartinEscribano P (2000) Measurement of pleural pressure during therapeutic thoracentesis. Am J Respir Crit Care Med 162: 1534-1538.

13. Feller-Kopman D, Walkey A, Berkowitz D, Ernst A (2006) The relationship of pleural pressure to symptom development during therapeutic thoracentesis. Chest 129: 1556-1560.

14. Cantey EP, Walter JM, Corbridge T, Barsuk JH (2016) Complications of thoracentesis: Incidence, risk factors, and strategies for prevention. Curr Opin Pulm Med 22: 378-385.
15. Lentz RJ, Lerner AD, Pannu JK, Merrick CM, Lance Roller, et al. (2019) Routine monitoring with pleural manometry during therapeutic large-volume thoracentesis to prevent pleural-pressure-related complications: A multicentre, single-blind randomized controlled trial. Lancet Respir Med 7: 447-455.

16. Petersen WG, Zimmerman R (2000) Limited utility of chest radiograph after thoracentesis. Chest 117: 1038-1042.

17. Aleman C, Alegre J, Armadans L, Andreu J, Falcó V, et al. (1999) The value of chest roentgenography in the diagnosis of pneumothorax after thoracentesis. Am J Med 107: 340343. 